\title{
Evaluation of nutritional status in children with amblyopia
}

\author{
Avaliação do estado nutricional de crianças com ambliopia \\ Sevgi Subasi', Ozgul Altintas², Selda Mercan³, Filiz Cizmecioglu4, Muge Toprak ${ }^{4}$ Esra Emre \\ 1. Department of Ophthalmology, Körfez State Hospital, Kocaeli, Turkey. \\ 2. Department of Ophthalmology, Acıbadem University Medical Faculty, Istanbul, Turkey. \\ 3. Forensic Toxicology Laboratory, Institute of Forensic Sciences, Istanbul University, Istanbul, Turkey. \\ 4. Division of Pediatric Endocrinology and Diabetes, Department of Pediatrics, Kocaeli University, Kocaeli, Turkey. \\ 5. Department of Ophthalmology, Gebze Fatih State Hospital, Kocaeli, Turkey. \\ 6. Department of Ophthalmology, Cerkezköy State Hospital, Tekirdağ, Turkey.
}

\begin{abstract}
Purpose: We aimed to compare the body mass index and vitamin and mineral status of children with and without amblyopia. Methods: Amblyopic children aged between 5 and 18 years $(n=46)$ and age-matched control children $(n=32)$ were evaluated in terms of anthropometric parameters, including height, weight, body mass index and demographic features. Serum vitamin $B_{12}$ and folate were measured using an Advia Centaur XP (Siemens, Ireland) biochemistry analyzer. We evaluated the inorganic mineral elements from hair samples with inductively coupled plasma-mass spectrometry using a Thermo XSeries 2 analyzer (Thermo Fisher Scientific, Bremen, Germany). Results: No significant difference was found between the two groups in terms of height, weight, and body mass index or serum $B_{12}$ and folate concentrations $(p>0.05)$. Children with severe amblyopia had lower vitamin $B_{12}$ and folate and higher body mass index. The levels of phosphorus $(p=0.012)$, selenium $(p=0.002)$, molybdenum $(p<0.001)$, iodine $(p=0.002)$, chromium $(p=0.022)$, boron $(p<0.001)$, and beryllium $(p=0.005)$ were all significantly lower in the amblyopia group compared to the control group. All of these minerals, except phosphorus, were also significantly lower in those with severe amblyopia compared to those with milder amblyopia and controls $(p<0.05)$.
\end{abstract}

\footnotetext{
Submitted for publication: May 31, 2017 Accepted for publication: June 22, 2018

Funding: This study was supported by the Kocaeli University Scientific Research Projects Coordination Unit (KOU-BAP: Project No. 2014/015).

Disclosure of potential conflicts of interest: None of the authors have any potential conflicts of interest to disclose.

Corresponding author: Sevgi Subasi

Gazanfer Bilge Bulvarı Akçakent 2 Sitesi C4/15 - Izmit - Kocaeli - Turkey E-mail: sevgiozel_5@hotmail.com

Approved by the following research ethics committee: Kocaeli University Medical Faculty \# KOU KAEK 2014/48).
}

Conclusion: Amblyopic children are significantly deficient in some inorganic elements. Inorganic elements, vitamin $B_{12}$, and folate may play an important role in the visual development of amblyopic children.

Keywords: Amblyopia; Body mass index; Vitamin $\mathrm{B}_{12}$; Folate; Humans; Child; Adolescent

RESUMO | Objetivo: Nosso objetivo foi comparar o índice de massa corporal e o nível de vitaminas e minerais de crianças com e sem ambliopia. Métodos: Crianças amblióticas com idades entre 5 e 18 anos $(n=46)$ e crianças controle pareadas por idade $(n=32)$ foram avaliadas quanto a parâmetros antropométricos, incluindo altura, peso, índice de massa corporal e características demográficas. A vitamina B12 e o folato séricos foram medidos utilizando um analisador bioquímico Advia Centaur XP (Siemens, Irlanda). Avaliamos os elementos minerais inorgânicos de amostras de cabelo com espectrometria de massa de plasma indutivamente acoplado usando um analisador Thermo XSeries 2 (Thermo Fisher Scientific, Bremen, Alemanha). Resultados: Não houve diferença significativa entre os dois grupos em relação à altura, peso e índice de massa corporal ou concentrações séricas de B12 e folato $(p>0,05)$. Crianças com ambliopia severa tinham menor vitamina B12 e folato e maior índice de massa corporal. Os níveis de fósforo $(p=0,012)$, selênio $(p=0,002)$, molibdênio $(p<0,001)$, iodo $(p=0,002)$, cromo $(p=0,022)$, boro $(p<0,001)$ e berílio $(p=0,005)$ foram todos significativamente menores no grupo com ambliopia em comparação com o grupo controle. Todos esses minerais, exceto o fósforo, também foram significativamente menores naqueles com ambliopia em comparação com aqueles com ambliopia leve e grupo controle $(p<0,05)$. Conclusão: As crianças amblíopes são significativamente deficientes em alguns elementos inorgânicos. Elementos inorgânicos, vitamina B12 e folato podem desempenhar um papel importante no desenvolvimento visual de crianças com ambliopia.

Descritores: Ambliopia; Índice de massa corporal; Vitamina B12; Ácido fólico; Humanos; Crianças; Adolescente 


\section{INTRODUCTION}

Amblyopia is associated with an increased risk of vision loss in the unaffected eye as well as lower educational and occupational opportunities ${ }^{(1)}$; however, treatment is generally successful and cost-effective. Traditional amblyopia therapy involves patching or restricting vision in the unaffected, preferred eye, particularly early in life. Recent data show that neuronal plasticity, which is present in children but inhibits amblyopia treatment in adults, is facilitated by calorie restriction ${ }^{(2)}$. Behavioral interventions such as enhanced sensory motor activity along with healthy diet planning are suggested as complementary strategies for current therapies of human amblyopia in adults. Calorie restriction is achieved by reducing caloric intake while maintaining essential nutritional requirements and is different from serious hunger ${ }^{(3)}$. Calorie restriction, particularly intermittent feeding, enhances neuronal plasticity and resistance to oxidative metabolic products ${ }^{(3)}$. Recent reports show that amblyopic children have higher body mass index (BMI) compared to normal children, suggesting that increased caloric intake may predispose to amblyopia ${ }^{(4)}$.

Ocular tissues contain high concentrations of mineral elements that play an important role in normal visual system functioning. Previous studies have shown that a deficiency of these elements could result in abnormalities in ocular tissues and functions ${ }^{(4-6)}$.

Vitamin $B_{12}$ and folate are required for DNA synthesis and cell division and support the proliferation of DNA, RNA, and protein synthesis ${ }^{(7)}$. In vivo and in vitro studies have shown that vitamin $B_{12}$ is necessary for nerve myelination and regeneration of degenerating motor nerve terminals, reduces glutamate toxicity, and improves nerve conduction ${ }^{(7)}$. In this context, vitamin $B_{12}$ is neuroprotective, and studies have shown that both folate and vitamin $B_{12}$ are essential for brain development ${ }^{(8,9)}$.

In the present study, we aimed to evaluate vitamin $B_{12}$ and folate concentrations in serum and inorganic elements in hair samples of amblyopic children and age-matched controls and compare anthropometric data, including BMl, between groups to investigate possible body habitus effects on amblyopia development.

\section{METHODS}

This prospective case-control study was conducted at Kocaeli University Training Hospital School of Medicine, Department of Pediatric Ophthalmology and Strabismus, in Kocaeli, Turkey, from March 2014 to November
2014 and included 32 healthy and 46 amblyopic children aged 5 to 18 years. The purpose and methods described adhered to the principles of the Declaration of Helsinki, and the study was approved by the local institutional review board. Inorganic analysis was performed at Istanbul University, Institute of Forensic Sciences. Parents provided informed consent prior to the ophthalmologic examination and completed a questionnaire which includes information about the subject's demographic status, including age, sex, smoke and alcohol exposure, additional vitamin intake, socioeconomic conditions (monthly income and living environment), and ocular and medical history.

Height and weight measurements were performed using a stadiometer (Seca 799, Hamburg, Germany). BMI was calculated as weight divided by height in meters squared $\left(\mathrm{kg} / \mathrm{m}^{2}\right)$. All anthropometric measurements were converted into standard deviation scores (SDS) based on the normative values for Turkish children ${ }^{(10)}$.

All subjects underwent a comprehensive eye examination, including best-corrected visual acuity (BCVA; measured using a Snellen chart at $5 \mathrm{~m}$ ), intraocular pressure (IOP) measurement, Hirschberg and prism cover test, slit-lamp and indirect fundus examination, and cycloplegic refraction following three applications of cyclopentolate $1 \%$ drops.

Amblyopia was defined as a difference of at least two lines on the Snellen chart between eyes on the BCVA test. IOP, anterior segment, and fundus examination were normal in all eyes. Amblyopia depth in the affected eye of each child was categorized as mild (BCVA $\geq 0.6$ ), moderate (BCVA $<0.6$ and $\geq 0.25$ ), or severe (BCVA $<0.25)$. Age-matched children with normal ocular findings were included as the control group.

Subjects were included if they had organic eye disease, history of intraocular surgery, cataract, glaucoma, laser treatment, or retinal or optic nerve disorders. Children with systemic diseases such as diabetes, hypertension, thyroid disease, gastrointestinal disease, and liver and kidney disease, which may interfere with the levels of vitamins and minerals, were excluded from the study.

EDTA blood samples $(5 \mathrm{~mL})$ were obtained from all children. Vitamin $B_{12}$ and folate concentrations were measured using an Advia Centaur XP analyzer (Siemens, Dublin, Ireland) using chemiluminescence.

\section{Inorganic elemental measurements sample preparation}

Scalp hair samples were collected from 46 amblyopic children and 32 age-matched controls. The occipital 
region of the scalp was used for sampling. Hair samples weighing approximately $0.5 \mathrm{~g}$ with a length of $3 \mathrm{~cm}$ were collected. The samples were transported sealed in paper to avoid contamination. Next, they were divided into approximately half $(0.25 \mathrm{~g})$ and cut into short pieces using sterilized scissors. They were washed in $50 \mathrm{~mL}$ of acetone, followed by two washes in 1:200 v/v Triton $\mathrm{X}-100$, then rinsed at least three times with ultra-pure water, re-washed with acetone twice, and dried in an oven at $75^{\circ} \mathrm{C}$. Once dry, the samples were weighed again and placed into Teflon perfluoroalkoxy (PFA) microwave vessels (XP-1500) with $10 \mathrm{~mL}$ of $65 \%$ nitric acid After 15 min, vessel bombs were prepared in a laminar flow cabinet and placed into the microwave digestion system. The digestion procedure was performed using a one-step temperature program in which the temperature was increased to $210^{\circ} \mathrm{C}$ over $20 \mathrm{~min}$ and then maintained for 10 min (maximum power: $1600 \mathrm{~W}$, pressure: $150 \mathrm{PSI}$ ). A blank acid sample was separately digested to ensure that there was no contamination from the reaction vessel. A reference standard of hair (NCS ZC81002b) was prepared in the same way as the samples for quality control and method validation. After digestion and cooling, the digests were transferred into volumetric flasks in the laminar flow cabinet and prepared to a volume of $50 \mathrm{~mL}$ with ultra-pure water. The final volume was prepared by 10 -fold dilution using $2 \%$ nitric acid and adding internal standards (20 $\mathrm{ng} \mathrm{m \textrm {m } ^ { - 1 }}$ of gallium and indium) prior to analysis.

\section{Instrumentation, reagents, and standards}

All measurements were made using a Thermo Scientific XSeries 2 instrument (Thermo Fisher Scientific, Bremen, Germany) operating at standard resolution and equipped with a CETAC, ASX-520 Autosampler (CETAC Technologies, Omaha, NE, USA). Sample digestion was performed in a closed vessel microwave digestion system (Mars, CEM Corporation, Matthews, NC, USA) equipped with pressure and temperature control sensors. A Millipore Direct-Q3 UV purification system (Millipore, Molsheim, France) was used to obtain ultra-pure water (18.2 $\mathrm{M} \Omega \mathrm{cm}$ ). The argon gas used for the inductively coupled plasma-mass spectrometry (ICP-MS) system was ultra-pure (99.999\% purity; Linde, Turkey). Super-pure quality (w/w) nitric acid $65 \%$ was purchased from Merck (Darmstadt, Germany). A tuning standard solution containing $10 \mu \mathrm{g} / \mathrm{mL}$ of barium (Ba), beryllium (Be), bismuth $(\mathrm{Bi})$, cerium $(\mathrm{Ce})$, cobalt $(\mathrm{Co})$, indium $(\mathrm{In})$, lead $(\mathrm{Pb})$, li- thium (Li), nickel (Ni), and uranium (U) in $2 \%$ nitric acid was obtained from High-Purity Standards (Charleston, SC, USA) and used at a concentration of $10 \mathrm{ng} / \mathrm{mL}$ prepared solution. A certificated calibration solution $\left(10 \mathrm{mg} / \mathrm{mL}^{-1}\right)$ was also purchased from High-Purity Standards. Indium (In) and gallium (Ga; $1000 \mathrm{mg} / \mathrm{mL}$ ) were used as internal standards (Absolute Standards, Inc., Hamden, CT, USA). Human hair (NCS ZC81002b) was used as a certified reference material and purchased from China National Analysis Center for Iron and Steel (Beijing, People's Republic of China).

All solutions were stored in high-density polyethylene bottles. Plastic and Teflon flasks were cleaned by soaking in $10 \%(\mathrm{v} / \mathrm{v})$ nitric acid for $8 \mathrm{~h}$ and rinsing twice with ultra-pure water prior to use.

\section{Calibration solutions}

The calibration curves were prepared in $2 \%$ nitric acid by incremental amounts of 0.0, 0.1, 0.2, 0.5, 1, 2, 5, 10, 20, 50, 100, and $150 \mathrm{ng} / \mathrm{mL}^{-1}$ for $\mathrm{Li}, \mathrm{Be}$, aluminum (Al), chromium $(\mathrm{Cr})$, manganese $(\mathrm{Mn}), \mathrm{Co}, \mathrm{Ni}$, copper $(\mathrm{Cu})$, arsenic (As), selenium (Se), strontium (Sr), molybdenum (Mo), cadmium (Cd), Ba, Pb, and U. Further calibration curves were prepared at 50,100, 150, 200, 250, 300, 400 , and $500 \mathrm{ng} / \mathrm{mL}^{-1}$ for $\mathrm{B}$, magnesium (Mg), phosphorous $(\mathrm{P})$, and zinc $(\mathrm{Zn})$. Only potassium $(\mathrm{K})$, calcium $(\mathrm{Ca})$, iodine (I), zirconium $(\mathrm{Zr})$, and tin ( $\mathrm{Sn})$ were calculated semi-quantitatively. Internal standards were added to all calibration solutions, which were prepared in triplicate.

\section{Statistical analysis}

All statistical analyses were performed using IBM SPSS Statistics for Windows version 20.0 (IBM Corp., Armonk, NY, USA). A Shapiro-Wilk test was used to assess the normality of the data. Normally and non-normally distributed continuous variables were expressed as medians $\left(25^{\text {th }}\right.$ to $75^{\text {th }}$ percentile), and categorical variables were summarized as counts (percentages). Student's $t$-test and oneway analysis of variance (ANOVA) were used to compare normally distributed continuous variables between groups. For non-normally distributed continuous variables, differences between groups were tested using Mann-Whitney $\mathrm{U}$ test and Kruskal-Wallis test. Tukey and Dunn's tests were used for multiple comparisons. Finally, associations between categorical variables were determined by Yates' and Fisher chi-square analysis, and those between continuous variables were determined by Spearman correlation analysis. A two-sided $p$ value $<0.05$ was considered statistically significant. 


\section{RESULTS}

\section{Demographic and anthropometric data}

Demographic data, including sex, age, height, and weight, are shown in table 1 . The median age values in the amblyopia and control groups were 9.3 years $(6.5-10.3)$ and 8.5 years (7.4-11.9), respectively. There were no significant differences in age, sex, height, height standard deviation score (SDS), weight SDS, BMI, or BMI SDS between groups. The median value of BMI was higher in severe amblyopia (18.00 [16.80-21.05]) and lower in mild amblyopia (16.30 [14.22-19.40]). There was no statistical difference between the amblyopia and control groups in terms of smoke and alcohol exposure, additional vitamin intake, and socioeconomic conditions. Unsurprisingly, BCVA and refractive power showed significant differences between the amblyopia and control groups $(p<0.001)$.

\section{Vitamin $B_{12}$ and folate data}

Vitamin $B_{12}$ and folate concentrations were evaluated in blood samples of 42 amblyopic and 32 control subjects. Vitamin $B_{12}$ concentration demonstrated a statistically significant difference across the amblyopia group when subdivided by severity and the control group $(p=0.045)$. No significant difference was found between folate concentrations in the different degrees of the amblyopia and control groups. The median vita- $\min \mathrm{B}_{12}$ and folate concentrations were lower in those with severe amblyopia and higher in those with mild amblyopia (Table 2).

\section{Elemental data}

All elemental concentrations were evaluated in the hair samples of 46 amblyopic and 27 control subjects. All linear calibration curves were acceptable, with a correlation coefficient of $R>0.999$. Acceptable recovery and precision (RSD\%) results were achieved using the certified reference material (80\%-110\% recovery). All RSD\% results were $<15 \%$, except Al. The mineral content in the amblyopia and control groups is shown in table 3. The concentrations of $\mathrm{P}, \mathrm{Se}, \mathrm{Mo}, \mathrm{l}, \mathrm{Cr}, \mathrm{B}$, and $\mathrm{Be}$ in the hair samples from amblyopic children were significantly lower than those in the control group (Table 3). The mineral content in children with differing degrees of amblyopia is shown in table 4. The concentrations of Se, Mo, l, B, and Be were statistically significantly different across the amblyopia group when subdivided by severity and the control group. Table 5 shows the correlations between vitamin $B_{12}$, folate, BMI SDS, and some elemental concentrations. Significant positive correlations were found between Ca and Mg; between I, Mo, and $\mathrm{Se}$; and between $\mathrm{Cr}, \mathrm{Ca}$, and $\mathrm{Mg}$. Negative correlations were found between $\mathrm{P}$ and $\mathrm{Ca}$, between $\mathrm{Mg}$ and $\mathrm{I}$, and between $\mathrm{B}, \mathrm{Ca}$, and $\mathrm{Mg}$ in the amblyopia and control groups, respectively.

Table 1. Demographic and anthropometric data of the amblyopia and control groups

\begin{tabular}{|c|c|c|c|}
\hline & Amblyopia $(n=46)$ & Control $(n=32)$ & $p$ value \\
\hline Female & $30(65.2 \%)$ & $16(50 \%)$ & 0.267 \\
\hline Age (years) & $9.30(6.57-10.32)$ & $8.55(7.40-11.90)$ & 0.270 \\
\hline \multicolumn{4}{|l|}{ Tobacco or alcohol exposure } \\
\hline No & $30(65.2 \%)$ & $18(56.3 \%)$ & 0.573 \\
\hline \multicolumn{4}{|l|}{ Additional vitamin intake } \\
\hline No & $45(97.8 \%)$ & $30(93.8 \%)$ & 0.565 \\
\hline \multicolumn{4}{|l|}{ Socioeconomic conditions } \\
\hline Monthly income (TL) & $1500(1075-2000)$ & $2000(1500-2700)$ & 0.078 \\
\hline Living environment (Town) & $41(89.1 \%)$ & $28(87.5 \%)$ & 1.00 \\
\hline Median Height (cm) & $132.50(127.00-142.62)$ & $137.50(130.62-156.00)$ & 0.116 \\
\hline Median Height SDS & $0.53(-0.68-1.19)$ & $0.71(-0.14-1.72)$ & 0.180 \\
\hline Median Weight (kg) & $30.40(24.60-41.50)$ & $34.50(26.10-50.55)$ & 0.393 \\
\hline Median Weight SDS & $0.23(-0.64-1.38)$ & $-0.18(-0.69-1.90)$ & 0.856 \\
\hline Median BMI (kg/cm²) & $17.45(14.97-20.60)$ & $16.65(14.72-20.77)$ & 0.835 \\
\hline Median BMI SDS & $-0.02(-0.96-1.09)$ & $-0.46(-1.13-0.83)$ & 0.506 \\
\hline
\end{tabular}

$\mathrm{n}=$ number of subjects; $\mathrm{SDS}=$ standard deviation score; $\mathrm{TL}=$ Turkish lira.

Continuous variables between groups were compared using the Mann-Whitney U test.

Categorical variables between groups were compared using Yates' chi-square test. 


\section{DISCUSSION}

Although many contributing factors may lead to amblyopia, the etiology is not clear. In this study, we investigated the relationship between amblyopia and BMI and vitamin and mineral content. We observed that some mineral element concentrations showed statisti- cally significant differences in amblyopic children when compared with age-matched healthy controls.

One factor that has been implicated in the occurrence of amblyopia is caloric intake. Recently, it has been shown that oral calorie restriction elicited increased neuronal plasticity in an animal model ${ }^{(3)}$. Studies have

Table 2. Comparison of BMI, BMI SDS, vitamin $B_{12}$, and folate in the amblyopia and control groups

\begin{tabular}{|c|c|c|c|c|}
\hline & BMI $\left(\mathrm{kg} / \mathrm{cm}^{2}\right)$ & BMI SDS & Vitamin $B_{12}(p m o l / L)$ & Folate (nmol/L) \\
\hline Amblyopia $(n=42)$ & $17.45(14.98-20.60)$ & $-0.02(-0.96-1.09)$ & $278.22(205.90-374.53)$ & $20.45(16.37-24.71)$ \\
\hline Mild $(n=16)$ & $16.30(14.22-19.40)$ & $-0.02(-1.23-1.31)$ & $330.62(278.22-422.13)$ & $21.52(17.73-28.72)$ \\
\hline Moderate $(n=17)$ & $17.30(15-23.50)$ & $-0.13(-0.94-1.44)$ & $255.34(208.11-376.01)$ & $20.97(17.82-25.05)$ \\
\hline Severe $(n=9)$ & $18.00(16.80-21.05)$ & $0.43(-0.87-0.93)$ & $205.90(158.67-287.82)$ & $18.89(14.22-25.62)$ \\
\hline Control $(n=32)$ & $16.65(14.73-20.78)$ & $-0.46(-1.13-0.83)$ & $306.27(224.72-328.77)$ & $20.45(16.37-24.71)$ \\
\hline $\mathrm{p}$ values & 0.517 & 0.912 & $0.045^{*}$ & 0.547 \\
\hline
\end{tabular}

$\mathrm{BMI}=$ body mass index; $\mathrm{SDS}=$ standard deviation score; $\mathrm{n}=$ number of subjects; $\mathrm{p}$ values demonstrate comparisons between controls and subjects with differing degrees of amblyopia. Kruskal-Wallis oneway ANOVA test was used to compare BMI, BMI SDS, vitamin $\mathrm{B}_{12}$, and folate. *Pairwise comparison is shown between mild and severe amblyopia.

Table 3. Mineral contents $\left(\mu \mathrm{g} \mathrm{g}^{-1}\right)$ in hair samples of amblyopia and control groups

\begin{tabular}{|c|c|c|c|}
\hline Element & Amblyopia $(n=46)$ & Control $(n=27)$ & $p$ values \\
\hline Calcium (Ca) & $691,17(337,33-1386,08)$ & $581,33(298,1-1435,67)$ & 0.522 \\
\hline Magnesium (Mg) & $52.67(30.50-122.30)$ & $49.30(21.16-109.90)$ & 0.349 \\
\hline Potassium (K) & $132.35(43.46-221.82)$ & $151.80(41.41-276.70)$ & 0.732 \\
\hline Phosphorus (P) & 145.15 (128.27-159.72) & $152.30(136.10-171.50)$ & 0.012 \\
\hline Zinc $(\mathrm{Zn})$ & $165.25(114.95-292.62)$ & $165.40(115.10-321.30)$ & 0.766 \\
\hline Copper $(\mathrm{Cu})$ & $10.16(8.64-14.34)$ & 11.39 (10.29-13.79) & 0.219 \\
\hline Lead $(\mathrm{Pb})$ & $1.41(0.79-2.33)$ & $1.35(0.98-2.79)$ & 0.627 \\
\hline Aluminum (Al) & $11.29(9.17-15.80)$ & $13.81(10.17-17.82)$ & 0.352 \\
\hline Selenium (Se) & $0.28(0.23-0.33)$ & $0.33(0.30-0.36)$ & 0.002 \\
\hline Molybdenum (Mo) & $0.05(0.04-0.06)$ & $0.07(0.06-0.10)$ & $<0.001$ \\
\hline lodine $(\mathrm{l})$ & $0.15(0.09-0.23)$ & $0.29(0.16-0.37)$ & 0.002 \\
\hline Chrome $(\mathrm{Cr})$ & $0.73(0.48-1.40)$ & $1.20(0.81-2.19)$ & 0.022 \\
\hline Manganese (Mn) & $0.51(0.32-0.72)$ & $0,51(0.34-0.71)$ & 0.914 \\
\hline Boron (B) & $0.94(0.33-1.74)$ & $2.13(1.37-2.58)$ & $<0.001$ \\
\hline Arsenic (As) & $0.07(0.04-0.10)$ & $0.06(0.04-0.09)$ & 0.697 \\
\hline Beryllium (Be) & $0.001(0.000-0.001)$ & $0.001(0.001-0.002)$ & 0.005 \\
\hline Lithium (Li) & $0.01(0.01-0.02)$ & $0.02(0.01-0.02)$ & 0.185 \\
\hline Uranium (U) & $0.02(0.01-0.04)$ & $0.01(0.01-0.04)$ & 0.438 \\
\hline Barium (Ba) & $0.55(0.43-1.01)$ & $0.56(0.52-0.97)$ & 0.784 \\
\hline Tin (Sn) & $0.18(0.08-0.39)$ & $0.28(0.17-0.43)$ & 0.082 \\
\hline Cadmium (Cd) & $0.02(0.01-0.05)$ & $0.02(0.02-0.04)$ & 0.260 \\
\hline Zirconium (Zr) & $0.03(0.03-0.04)$ & $0.04(0.03-0.05)$ & 0.670 \\
\hline Strontium (Sr) & $2.08(0.99-4.82)$ & $1.76(0.90-4.24)$ & 0.560 \\
\hline Nickel (Ni) & $0.63(0.46-1.12)$ & $0.85(0.66-1.12)$ & 0.153 \\
\hline Cobalt (Co) & $0.02(0.01-0.02)$ & $0.02(0.01-0.03)$ & 0.501 \\
\hline
\end{tabular}

$\mathrm{n}=$ number of subject.

All except phosphorus were normally distributed and compared with student's $t$ test, and for phosphorus Mann-Whitney U Test was used.

Comparisons are significant at the $\mathrm{p}<0.05$ level. 
Table 4. Comparison of mineral contents $\left(\mu \mathrm{g} \mathrm{g}^{-1}\right)$ in hair samples between controls and subjects with differing degrees of amblyopia

\begin{tabular}{|c|c|c|c|c|c|}
\hline & Control $(n=27)$ & Mild $(n=18)$ & Moderate $(n=19)$ & Severe $(n=9)$ & $p$ value \\
\hline$P$ & $152.30(136.10-171.50)$ & $143.00(130.80-161.42)$ & $148.00(129.40-161.50)$ & $136.80(117.55-155.95)$ & 0.95 \\
\hline Se & $0.33(0.30-0.36)$ & $0.28(0.22-0.32)$ & $0.29(0.25-0.35)$ & $0.23(0.20-0.32)$ & $0.008^{1,3}$ \\
\hline Mo & $0.07(0.06-0.10)$ & $0.05(0.04-0.07)$ & $0.05(0.04-0.06)$ & $0.05(0.03-0.05)$ & $<0.001^{1,2,3}$ \\
\hline l & $0.29(0.16-0.37)$ & $0.17(0.09-0.31)$ & $0.15(0.07-0.21)$ & $0.15(0.10-0.23)$ & $\mathbf{0 . 0 1 6} 6^{1,2,3}$ \\
\hline $\mathrm{Cr}$ & $1.20(0.81-2.19)$ & $0.64(0.39-1.35)$ & $0.97(0.55-1.79)$ & $0.85(0.44-1.26)$ & 0.059 \\
\hline B & $2.13(1.37-2.58)$ & $1.36(0.41-1.82)$ & $0.68(0.27-1.73)$ & $0.94(0.09-1.57)$ & $0.001^{2,3}$ \\
\hline $\mathrm{Be}$ & $0.001(0.001-0.002)$ & $0.001(0.001-0.001)$ & $0.000(-0.001-0.002)$ & $0.000(-0.001-0.001)$ & $0.008^{2,3}$ \\
\hline
\end{tabular}

$\mathrm{n}=$ number of subjects. $\mathrm{p}$ values demonstrate comparisons among groups with mild, moderate, and severe amblyopia and control groups using the Kruskal-Wallis test. Pairwise comparisons are shown $=1$ between mild amblyopia and control, ${ }^{2}$ between moderate amblyopia and control, and ${ }^{3}$ between severe amblyopia and control.

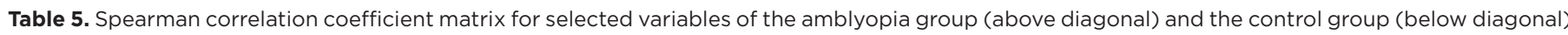

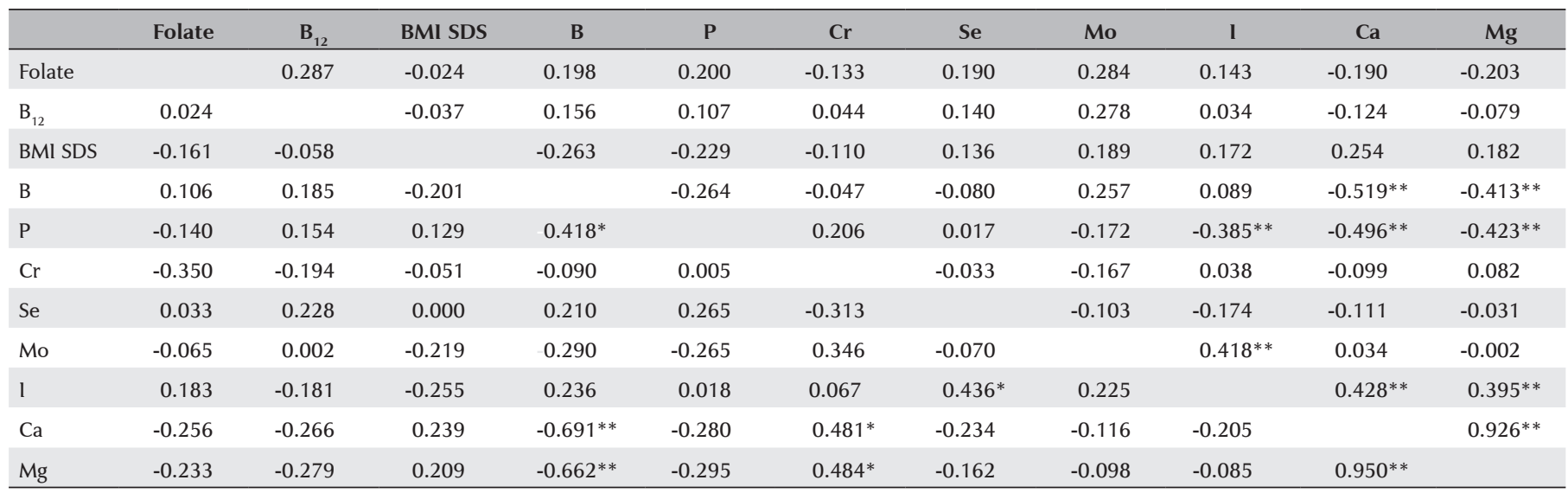

$\mathrm{SDS}=$ standard deviation score, ${ }^{*}=$ correlation is significant at the 0.05 level, ${ }^{* *}=$ correlation is significant at the 0.01 level.

also reported that amblyopic children have increased $\mathrm{BMI}^{(4)}$; however, our results are not consistent with this finding possibly because of the relatively small sample size of our severe amblyopia group. Further larger studies are needed to clarify the effect of BMI on amblyopia development.

Vitamin $B_{12}$ and folate deficiencies are known to impair axonal transport and neuronal regeneration. Visual evoked potential studies have shown demyelination in the white matter of the spinal cord and optic nerve in patients with vitamin $B_{12}$ deficiency ${ }^{(11-13)}$. In our study, vitamin $B_{12}$ and folate concentrations in amblyopic children were similar to those in the control subjects. However, when examining these concentrations in amblyopic children with different degrees of severity, the mean concentrations of vitamin $B_{12}$ and folate decrease as the disease severity increases. Unfortunately, owing to the small group size, it was not possible to distinguish between amblyopia severity and vitamin $B_{12}$ and folate concentration differences. Larger sample studies are ne- eded to determine the relationship between amblyopia severity and vitamin $B_{12}$ and folate concentrations. We hope that publication of our data will stimulate further work with larger sample sizes to clarify this relationship.

Inorganic elemental concentrations were measured using hair samples to reflect long-term concentrations in the body and thus general dietary intake ${ }^{(14)}$. The $\mathrm{Mg}$ and $\mathrm{Ca}$ levels in the hair of amblyopic children were higher than those in the control group but did not reach statistical significance. Mg blocks $\mathrm{N}$-methyl-D-aspartate (NMDA) receptors, and Ca causes neurotoxicity via the NMDA receptors. Visual system development includes the activation of the NMDA receptors, but this process is inhibited in high $\mathrm{Mg}$ concentrations ${ }^{(15,16)}$. The relationship between Ca, Mg, NMDA, and amblyopia was discussed in a recent study ${ }^{(4)}$.

Boron is vital for some enzymatic reactions as it maintains the integrity and function of cell membranes. It is an important element that increases $\mathrm{Ca}$ and $\mathrm{Mg}$ metabolism while decreasing their urinary excretion ${ }^{(17,18)}$. 
Boron is involved in regulating nicotinamide adenine dinucleotide phosphate, which, in turn, is important for the degradation of oxidative glutathione. Glutathione is an antioxidant substrate; hence, boron is an important mineral element for antioxidant defense mechanisms ${ }^{(19)}$. In the present study, boron levels were significantly lower in amblyopic patients. As might be expected, the concentrations of $\mathrm{Ca}$ and $\mathrm{Mg}$ increased in both the amblyopia and control groups as the boron levels increased; this relationship is shown in Table 5 as a negative correlation.

A selenium-deficient diet in rats reduces cell numbers in the inner retinal nuclear layer, decreases horizontal and amacrine cell nucleus, and causes some neuronal injuries ${ }^{(20)}$. Selenium is also an important antioxidant element, and its effects on the eyes have been demonstrated in many clinical and experimental studies. Selenium deficiency is reported to cause oxidative stress in the corneal epithelium, resulting in corneal damage. Thus, selenium has been suggested to help in the treatment of dry eyes ${ }^{(5)}$. In another study, low serum selenium in myopic children was associated with the development of myopia ${ }^{(6)}$. Therefore, selenium appears to have an important role in the normal development and function of the visual apparatus. In the present study, we also found a significantly reduced concentration of Se in amblyopic children compared to controls. Both boron and selenium are important mineral regulators of antioxidant function and may play an important role in maintaining optic nerve health and amblyopia. We suggest that dietary supplements containing selenium and perhaps boron should be considered for amblyopic children.

Molybdenum is a cofactor of the enzymes sulfite oxidase and xanthine oxidase. Molybdenum deficiency is typically considered a metabolic disease and is characterized by a defect in psychomotor functioning. A correlation has been found between molybdenum and both selenium and iodine $\mathrm{e}^{(21)}$. As a component of both tri-iodothyronine (T3) and tetra-iodothyronine (T4) thyroid hormones, iodine is critical for normal thyroid function, and selenium is a cofactor for thyroperoxidase, an enzyme catalyzing the production of these hormones in the thyroid gland. Recent studies have shown that molybdenum-deficient patients have a tendency to develop hypothyroidism ${ }^{(21)}$. The present study showed that the levels of these elements were decreased in amblyopic children. Further studies are required to investigate any relationship between thyroid function and amblyopia.
A major limitation of this study was its small sample size, especially in the severe amblyopia group; hence, this group needs further study with more subjects, which could affect the statistical analysis of the results. However, we believe that our results are intriguing and that large-scale studies should be performed to further investigate the possible relationships between inorganic elements and amblyopia.

In conclusion, amblyopic children have low levels of selenium, iodine, molybdenum, boron, and beryllium, suggesting that deficiencies of these elements could be related to visual development abnormalities either via excessive oxidative stress, thyroid hypoactivity, or both. Therefore, pediatric ophthalmologists should consider the nutritional status when assessing amblyopic children. Further studies are needed to investigate the effects of these elements on the etiology and pathophysiology of amblyopia.

\section{REFERENCES}

1. Leon A, Donahue SP, Morrison DG, Estes RL, Li C. The age-dependent effect of anisometropia magnitude on anisometropic amblyopia severity. JAAPOS. 2008;12(2):150-6.

2. Spolidoro M, Baroncelli L, Putignano E, Maya-Vetencourt JF, Viegi A, Maffei L. Food restriction enhances visual cortex plasticity in adulthood. Nat Commun. 2011;2:320.

3. Maya-Vetencourt JF, Origlia N. Visual cortex plasticity: a complex interplay of genetic and environmental influences. Neural Plast. 2012;2012:631965.

4. Zhu Q, Chen J, Zheng M, Chen L, Liu J, Tian J, et al. Mineral elements in the hair of amblyopic children. Biol Trace Elem Res. 2011; 141(1-3):119-25.

5. Higuchi A, Takahashi K, Hirashima M, Kawakita T, Tsubota K. Selenoprotein P controls oxidative stress in cornea. PLoS One. 2010; 5(3):e9911.

6. Fedor M, Socha K, Urban B, Soroczyńska J, Matyskiela M, Borawska $\mathrm{MH}$, et al. Serum concentration of zinc, copper, selenium, manganese, and $\mathrm{cu} / \mathrm{zn}$ ratio in children and adolescents with myopia. Biol Trace Elem Res. 2017;176(1):1-9.

7. Akaike A, Tamura Y, Sato Y, Yokota T. Protective effects of a vitamin B12 analog, methylcobalamin, against glutamate cytotoxicity in cultured corticalneurons. Eur J Pharmacol. 1993;241(1):1-6.

8. Scalabrino G. The multi-faceted basis of vitamin B12 (cobalamin) neurotrophism in adult central nervous system: lessons learned from its deficiency. Prog Neurobiol. 2009;88:203-20.

9. McGarel C, Pentieva K, Strain JJ, McNulty H. Emerging roles for folate and related B-vitamins in brain health across the lifecycle. Proc Nutr Soc. 2015;74(1):46-55.

10. Neyzi O, Bundak R, Gökçay G, Günöz H, Furman A, Darendeliler F, et al. Reference values for weight, height, head circumference, and body mass index in turkish children.J Clin Res Pediatr Endocrinol. 2015;7(4):280-93.

11. Misra UK, Kalita J, Das A. Vitamin B12 deficiency neurological syndromes: a clinical, MRI and electro diagnostic study. Electromyogr Clin Neurophysiol. 2003;43(1):57-64. 
12. Pandey S, Kalita J, Misra UK. A sequential study of visual evoked potential in patients with vitamin B12 deficiency neurological syndrome. Clin Neurophysiol. 2004;115(4):914-918.

13. Puri V, Chaudhry N, Goel S, Gulati P, Nehru R, Chowdhury D. Vitamin B12 deficiency: a clinical and electrophysiological profile. Electromyogr Clin Neurophysiol. 2005;459(5):273-84.

14. Pasha Q, Malik SA, Shaheen N, Shah MH. Comparison of trace elements in the scalp hair of malignant and benign breast lesions versus healthy women. Biol Trace Elem Res. 2010;134(2):160-73.

15. Murphy KM, Duffy KR, Jones DG. Experience-dependent changes in NMDAR1 expression in the visual cortex of an animal model for amblyopia. Vis Neurosci. 2004;21(4):653-70.

16. Kato N, Yoshimura H. Reduced Mg2 + block of N-methyl-D-aspartate receptor-mediated synaptic potentials in developing visual cortex. Proc Natl Acad Sci USA. 1993;190(15):7114-8.

17. Gümüşderelioğlu M, Tunçay EÖ, Kaynak G, Demirtaş TT, Aydın ST,
Hakkı SS. Encapsulated boron as an osteoinductive agent for bone scaffolds. J Trace Elem Med Biol. 2015;31:120-8.

18. Beattie JH, Peace HS. The influence of a low boron diet and boron supplementation on bone, major mineral and sex steroid metabolism in postmenopausal women. Br J Nutr. 1993;69(3):871-84.

19. Doğan A, Demirci S, Apdik H, Bayrak OF, Gulluoglu S, Tuysuz EC, et al. A new hope for obesity management: Boron inhibits adipogenesis in progenitor cells through the $\mathrm{Wnt} / \beta$-catenin pathway. Metabolism. 2017;69:130-42.

20. Amemiya T. Retinal changes in the selenium deficient rat. Int J Vitam Nutr Res. 1985;55(3):233-7.

21. Çelik T, Savaş N, Kurtoğlu S, Sangün Ö, Aydın Z, Mustafa D, et al. lodine, copper, zinc, selenium and molybdenum levels in children aged between 6 and 12 years in the rural area with iodine deficiency and in the city center without iodine deficiency in Hatay. Turk Pediatri Ars. 2014;49(2):111-6. 